\title{
Eradication rates, risk factors, and implant selection in two-stage revision knee arthroplasty: a mid-term follow-up study
}

Steffen Hoell ${ }^{1 *}$, Anna Sieweke ${ }^{2}$, Georg Gosheger², Jendrik Hardes², Ralf Dieckmann², Helmut Ahrens ${ }^{2}$ and Arne Streitbuerger ${ }^{2}$

\begin{abstract}
Background: Two-stage revision (TSR) knee arthroplasty is an established treatment, but failure to control infection still occurs in 4-50\% of cases. The aim of this study was to assess the infection eradication rate, risk factors for failure, and the clinical outcome after two-stage revision knee arthroplasty.

Methods: This retrospective study included 59 patients who had undergone at least one two-stage revision procedure due to periprosthetic joint infection (PJI). Demographic data, comorbidities, types of implant, and complications were analyzed. Univariate and multivariate logistic regression analysis were used to identify risk factors for failure.
\end{abstract}

Results: The infections were controlled in 55 patients (93.2\%). The follow-up period was 4.1 ( \pm 2.7$)$ years. Infection control was achieved after the first TSR in 42 patients (71.2\%) and after the second TSR in 13 (76.5\%). The percentage of arthrodesis procedures in patients with infection control increased from $16.75 \%$ after one TSR to 69. $2 \%$ after two TSRs. Multivariate logistic regression analysis identified body mass index (BMI) (odds ratio 1.22; $95 \%$ confidence intervals, 1.07 to 1.40; $p=0.004)$ and smoking (OR $21.52 ; 95 \% \mathrm{Cl}, 2.60$ to $178.19 ; p=0.004)$ as risk factors for failure.

Conclusions: Two-stage revision protocols can achieve acceptable results even after a second procedure. It is still unclear whether the choice of implant influences failure rates. Risk factors for failure after two-stage revision were identified. Studies with larger sample sizes are needed in order to support these findings and identify further risk factors. To reduce failure rates, programs should be established to treat or minimize risk factors in patients with PJI.

Keywords: Two-stage revision knee arthroplasty, Arthrodesis, Risk factor, Periprosthetic joint infection, BMI, Nicotine abuse

Abbreviations: BMI, Body mass index; Cl, Confidence interval; CRP, C-reactive protein; OR, Odds ratio; PJI, Periprosthetic joint infection; SD, Standard deviation; TKA, Total knee arthroplasty; TSR, Two-stage revision

\section{Background}

Several studies have identified comorbidities and conditions that increase the rate of periprosthetic joint infection (PJI) after primary hip and knee arthroplasty [1-8]. In two-stage revision (TSR) surgery, protocols involving the implantation of an antibiotic-loaded bone-cement

\footnotetext{
*Correspondence: st.hoell@web.de

'Department of Orthopaedics, Paracelsus Hospital, Am Natruper Holz 69, 49076 Osnabrück, Germany

Full list of author information is available at the end of the article
}

spacer have become the gold standard for treating periprosthetic infections.

Radical debridement with explantation of the prosthesis and supportive administration of antibiotics are the most important pillars for controlling PJI $[9,10]$, but reinfection rates after TSR continue to be high. Reinfection rates reported in the literature range from 4 to $50 \%$ $[3,4,11-16]$. Only a few studies have analyzed the factors that have a negative impact on infection control after TSR [17-20]. In order to minimize failure rates in TSR, evaluated treatment protocols and diagnostic 
algorithms are needed, and it should be possible to identify patients who are at higher risk of failure. Once risk factors have been identified, further investigations and additional treatments can help reduce failure rates.

The aim of the present study was to investigate the extent to which infection can be successfully controlled after two-stage revision knee arthroplasty and identify factors that influence the failure rate.

\section{Methods}

Seventy patients who underwent two-stage revision knee arthroplasty between 2004 and 2008 in our department were identified. The following criteria were used to define PJI: sinus tract communicating with the prosthesis and/or at least two identical positive cultures identified intraoperatively $[21,22]$. All infections were defined as delayed or late chronic [23].

Seven patients had died and four patients declined to participate in the study, and a total of 59 patients were therefore included. Their average age at follow-up was 73 years $( \pm 9.7)$, and there were 32 men and 27 women. The patients were all referred to our institution as a tertiary center. The protocol consisted of explantation of the prosthesis with implantation of a fixed antibioticloaded bone-cement spacer (Refobacin ${ }^{\circ}$ Revision bone cement; Biomet Inc., Warsaw, Indiana, USA; 1 g gentamicin and $1 \mathrm{~g}$ clindamycin/40 g cement) and at least 14 days of intravenous antibiotic administration, followed by at least 4 weeks of antibiotics orally. If necessary, additional antibiotics were mixed into the spacer, depending on the microbiological results, as an off-label application. All antibiotic treatments were administered in collaboration with the hospital's Institute of Microbiology. After an interval of 14 days without antibiotics, C-reactive protein (CRP) was measured in serum. The second-stage procedure was performed 9-12 weeks after explantation.

The criteria for reimplantation were no sinus track, no signs of local inflammation, and serum CRP values that had declined during the period since explantation. The definition of infection control was no subsequent surgical intervention for infection at the time of follow-up. Eleven potential risk factors were documented from the demographic data, comorbidities, and postoperative complications.

The criteria for arthrodesis ( $n=18$ patients) were an insufficient extension mechanism and/or clearly compromised capsule and soft-tissue conditions, with a high risk of postoperative wound healing problems and limited function. The indication for arthrodesis was based on the personal judgment and experience of the surgeon and the patient's consent. None of the patients underwent additional soft-tissue coverage with local muscle flaps.

\section{Statistical analysis}

Means plus or minus standard deviation (SD), ranges, and proportions were calculated to analyze the different characteristics in the cases of two-stage knee revision. Statistical significance was assessed using the chisquared test, Fisher's exact test, Student's $t$ test, and the Mann-Whitney $U$ test.

The probability of failed infection control was modeled using univariate binary logistic regression. Odds ratios, the corresponding $95 \%$ confidence intervals, and Waldtype $p$ values were calculated. In a second step, variables were selected in a stepwise fashion, applying backward selection to variables in the univariate logistic regression. All inferential statistics are intended to be exploratory, not confirmatory, and are interpreted accordingly. The comparison-wise type 1 error rate is controlled instead of the experiment-wise error rate. The local significance level was set to 0.05 .

No adjustment for multiple testing was performed. Statistical analyses were performed using IBM SPSS ${ }^{\circ}$ Statistics for Windows, version 21 (IBM Corporation, Armonk, NY, USA).

\section{Results}

Infection control was achieved in 55 patients (93.2 \%). The follow-up period was 4.1 years ( \pm 2.7 years). Infection control was achieved after the first TSR in 42 patients $(71.2 \%)$ and after the second TSR in 13 patients (76.5\%). There were no significant differences between the first and second TSRs $(p>0.05)$. The percentage of arthrodesis in patients with infection control increased from $16.75 \%$ after one TSR to $69.2 \%$ after two TSRs. The average time from reimplantation to reinfection was 2.3 years (range $0.6-3.7$ years).

The amputation rate when infection could not be controlled was $6.8 \%$ (4/59); amputations were required in one patient with an arthrodesis and three with revision endoprostheses. Figure 1 shows the clinical course for all of the patients. The risk factors investigated and the results of the univariate logistic regression are listed in Table 1. Although patients who had Staphylococcus epidermidis at the first revision had the highest failure rate (35.3\%), statistical analysis was not performed due to the small number of cases. Table 2 presents the results of the multivariate logistic regression analysis after variable selection. Table 3 shows the organisms that were cultured in patients with recurrent infections and the choice of implant. Identical bacteria were found at the second TSR in eight of the 17 patients concerned $(47.1 \%)$.

\section{Discussion}

Periprosthetic joint infection (PJI) is one of the most severe complications that occur in patients who undergo 


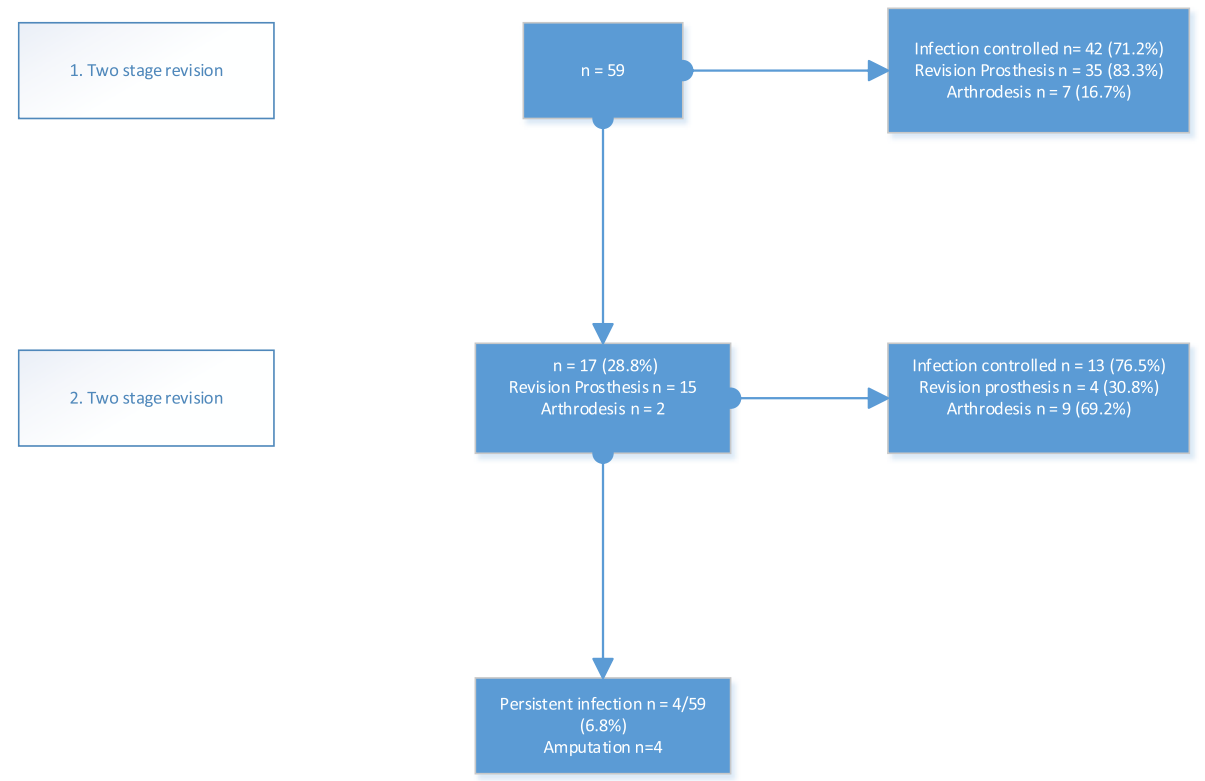

Fig. 1 Flowchart of all patients

total knee arthroplasty (TKA). Two-stage revision is still the gold standard for treatment of PJI, although onestage revisions may achieve similar results in special conditions [24-28]. Nevertheless, reinfection rates vary from 4 to $50 \%[3,4,11-16]$. Among the patients included in the present study, successful treatment was achieved in 55 (93.2 \%) after a mean follow-up period of 4.1 years.

There were no differences in the success rates between patients who underwent one TSR procedure and those with two procedures. Lower eradication rates have been reported in the literature after a second TSR [29], but a high rate of arthrodesis in the second TSRs might be an explanation for this. Isiklar et al. recommended arthrodesis instead of multiple revisions in patients with chronic infections, in order to avoid amputation [15].

Other studies have also reported higher rates of infection control with arthrodesis in comparison with revision prostheses $[2,11,16,30]$. In contrast to these results, a $50 \%$ failure rate after septic arthrodesis was reported in 2015 [31].

In view of the small numbers of arthrodeses, statistical analysis was not carried out in the present study and no conclusions can therefore be drawn on whether or not arthrodesis is in fact associated with lower reinfection rates.

It has to be discussed if allograft reconstruction of the extensor mechanism is an alternative instead of arthrodesis. Although it is known that allograft reconstructions show high rates of complications the benefit of a better mobility must be considered. In a study from 2016 in 26 knees, $69 \%$ of the allografts could be retained at a follow-up of 68 months with a reoperation rate of $58 \%[32,33]$.

However, it is not only the type of treatment administered that is responsible for the clinical outcome. It is known from several studies that comorbidities and other conditions can have a negative influence on infection rates after primary arthroplasty [1-8]. The causes of failure after TSR are rarely reported [17-20].

The most frequent potential risk factors for failure were analyzed in the patients included in the present study. Among the comorbid conditions present, diabetes was identified as a risk factor, with an OR of 6.65 (95\% CI, 1.62 to 27.30) in the univariate analysis. Another study published in 2015 also found that diabetes had a significantly higher prevalence in the group with reinfections [19]. By contrast, Sakellariou et al. did not find any significant differences in a univariate analysis of 110 patients with TSR [18]. Among the local conditions that were present, fistulas were found to be a relevant factor in the univariate analysis. This finding is supported by a study also published in 2015, in which fistulas were associated with recurrent infection even in the multivariate logistic regression analysis [20].

A medical history including periprosthetic fracture around the knee was identified as a risk factor for failure after the first TSR. In an earlier study, our group showed that septic failure of revision arthroplasty with megaprostheses was strongly associated 
Table 1 Potential risk factors for faiure that were investigated with univariable logistic regression

\begin{tabular}{|c|c|c|c|c|c|c|}
\hline & & Infection controlled after the first TSR & Fialure after the first TSR & $P$ value & Odds ratio & $\mathrm{Cl}(95 \%)$ \\
\hline Sinus present & & & & 0.008 & 5.24 & $1.55-17.65$ \\
\hline Yes & $n=19$ & $N=10$ & $N=9$ & & & \\
\hline No & $n=40$ & $N=35$ & $N=5$ & & & \\
\hline Diabetes & & & & 0.009 & 6.65 & $1.62-27.3$ \\
\hline Yes & $n=11$ & $n=4$ & $n=7$ & & & \\
\hline No & $n=48$ & $n=38$ & $n=10$ & & & \\
\hline Smoking & & & & 0.018 & 8.33 & $1.43-48.54$ \\
\hline Yes & $n=7$ & $N=3$ & $N=4$ & & & \\
\hline No & $n=52$ & $N=42$ & $N=10$ & & & \\
\hline $\mathrm{BMI}>30$ & & & & 0.033 & 5.74 & $1.15-28.62$ \\
\hline Yes & $n=37$ & $n=24$ & $n=13$ & & & \\
\hline No & $n=22$ & $n=17$ & $n=5$ & & & \\
\hline Periprosthetic fracture & & & & 0.034 & 3.57 & $1.1-11.57$ \\
\hline Yes & $n=23$ & $n=14$ & $N=9$ & & & \\
\hline No & $n=36$ & $n=28$ & $N=8$ & & & \\
\hline Wound healing problems & & & & 0.061 & 3.16 & $0.95-10.55$ \\
\hline Yes & $n=17$ & $N=10$ & $N=7$ & & & \\
\hline No & $n=42$ & $N=35$ & $N=7$ & & & \\
\hline Corticosteriods & & & & 0.076 & 8.38 & $0.8-87.11$ \\
\hline Yes & $n=4$ & $N=2$ & $N=2$ & & & \\
\hline No & $n=55$ & $N=43$ & $N=12$ & & & \\
\hline Immune suppression & & & & 0.191 & 5.2 & $0.44-61.67$ \\
\hline Yes & $N=1$ & $N=2$ & & & & \\
\hline No & $N=45$ & $N=11$ & & & & \\
\hline Postoperative hematoma & & & & 0.418 & 1.67 & $0.48-5.8$ \\
\hline Yes & $n=16$ & $N=11$ & $N=5$ & & & \\
\hline No & $n=43$ & $N=29$ & $N=14$ & & & \\
\hline Blood transfusion & & & & 0.458 & 2.37 & $0.24-23.1$ \\
\hline Yes & $n=44$ & $N=28$ & $N=16$ & & & \\
\hline No & $n=15$ & $N=14$ & $N=1$ & & & \\
\hline Tumor disease & & & & 0.986 & 1.02 & $0.18-5.91$ \\
\hline Yes & $n=7$ & $N=5$ & $N=2$ & & & \\
\hline No & $n=52$ & $N=40$ & $N=12$ & & & \\
\hline
\end{tabular}

$P$ value, significance level was set to 0.05

Table 2 Comorbid conditions or patterns that were identified by variable selection as risk factors in a multivariable logistic regression

\begin{tabular}{llcl}
\hline & $P$ & Odds ratio & $\mathrm{Cl}(95 \%)$ \\
\hline Body mass index $\left(\mathrm{kg} / \mathrm{m}^{2}\right)$ & 0.004 & 1.22 & $1.07-1.40$ \\
Nicotine abuse & 0.004 & 21.52 & $2.60-178.19$ \\
\hline
\end{tabular}

with a medical history of periprosthetic fractures around the knee [13].

Suzuki et al. investigated the influence of surgical procedures in the region of the knee joint. They observed significantly more frequent infections with open reduction and internal fixation after trauma to the knee joint and when osteosynthesis material remained in situ [7].

Two risk factors were identified in the multivariate logistic regression analysis in the present study: body mass index (BMI) and smoking. An increase in the BMI by 
Table 3 Patients with recurrent infection

\begin{tabular}{|c|c|c|c|c|}
\hline Patients & Culture during the first TSR & Culture during the second TSR & Implant after the first TSR & Outcome after the second TSR \\
\hline 1 & Staph aureus & Staph aureus & Revision prosthesis & Revision prosthesis \\
\hline 2 & Staph aureus & Staph aureus & Revision prosthesis & Revision prosthesis \\
\hline 3 & Staph aureus & Staph aureus & Revision prosthesis & Revision prosthesis \\
\hline 4 & Staph epi & Staph epi & Revision prosthesis & Arthrodesis \\
\hline 5 & Staph epi & Staph epi & Revision prosthesis & Arthrodesis \\
\hline 6 & Staph epi & Staph epi & Revision prosthesis & arthrodesis \\
\hline 7 & Staph epi & Staph epi & Revision prosthesis & Revision prosthesis \\
\hline 8 & Staph capitis & Staph capitis & Revision prosthesis & Arthrodesis \\
\hline 9 & Staph epi & Staph haemolyticus & Revision prosthesis & Arthrodesis \\
\hline 10 & Staph epi & MRSA & Revision prosthesis & Arthrodesis \\
\hline 11 & Staph epi & MRSA & Revision prosthesis & Amputation \\
\hline 12 & Staph epi & MRSA & Revision prosthesis & amputation \\
\hline 13 & Enterobacter faecalis & E. coli & Revision prosthesis & Arthrodesis \\
\hline 14 & Staph aureus & Staph epi & Revision prosthesis & amputation \\
\hline 15 & Staph simulans & Staph epi & Revision prosthesis & Arthrodesis \\
\hline 16 & $\begin{array}{l}\text { Staphylococcus hominis } \\
\text { Streptococcus acidominimus }\end{array}$ & Candida albicans & arthrodesis & amputation \\
\hline 17 & $\begin{array}{l}\text { Staphylococcus epidermidis/ } \\
\text { Klebsiella oxytoca/Pseudomonas } \\
\text { aeruginosa/Enterococcus faecalis }\end{array}$ & Candida albicans & Revision prosthesis & Arthrodesis \\
\hline
\end{tabular}

one point showed an increased risk for failure of about $22 \%$. However, Mortazavi et al. did not observe any association between BMI and persistent PJI after two-stage TKA [25]. Kubista et al. distinguished between BMI scores of $<25,25-35$, and $>35$.

No significant differences were observed between these groups with regard to the rates of persistent infection after two-stage TKA [34]. In a matched-cohort study, patients with a $\mathrm{BMI}>40 \mathrm{~kg} / \mathrm{m}^{2}$ had a $22 \%$ risk for reinfection in comparison with patients with a BMI $<30 \mathrm{~kg} / \mathrm{m}^{2}$, at $4 \%$ [35]. In two-stage revision hip arthroplasty, obesity has also been found to be a significant risk factor for failure [36]. Higher rates of recurrent infection have also been reported among smokers, with a $71.4 \%$ rate of persistent or recurrent infection after the first two-stage replacement in comparison with only $23.1 \%$ in nonsmokers [6, 7, 37]. These results were confirmed in the present cohort.

The study has several limitations. As all of the patients were referred to the department, it was not possible to record all relevant factors. For example, the number of previous revision procedures was unclear and could not be analyzed, although it is known that this factor has a negative influence on complication rates $[13,17]$. Due to the relatively small number of patients who underwent arthrodesis, statistical analysis was not useful. The wide variety of bacteria identified also made it impossible to carry out statistical analysis.

\section{Conclusions}

Two-stage revision (TSR) protocols can achieve acceptable results even when they are repeated. Amputation rates can be kept low. It is still unclear whether the choice of implant has an influence on failure rates. Risk factors for failure after two-stage revision have been identified, but studies with larger numbers of patients are needed in order to support these findings and identify further risk factors. In order to reduce failure rates, programs should be established for treating or minimizing risk factors in patients with periprosthetic joint infection.

\section{Acknowledgements \\ None. \\ Funding \\ The study was not funded. \\ Availability of data and material \\ Not applicable.}

\section{Authors' contributions}

SH made substantial contribution to conception and design; AS made substantial contribution to acquisition of the data and critical revision of the manuscript; GG made critical revision of the manuscript for content; $\mathrm{JH}$ made contribution to analysis and interpretation of the data; RD made substantial contribution to acquisition of the data; HA made contribution to 
analysis and interpretation of the data. All authors read and approved the final manuscript.

\section{Competing interests}

The authors declare that they have no competing interests.

\section{Consent for publication}

Consent for publication was obtained from the participants.

\section{Ethics approval and consent to participate}

Ethics approval was not necessary, as confirmed by the local ethics committee at the University of Münster, Germany (ref. 2016-309-f-N).

\section{Author details}

'Department of Orthopaedics, Paracelsus Hospital, Am Natruper Holz 69, 49076 Osnabrück, Germany. ${ }^{2}$ Department of General Orthopaedics and Tumor Orthopaedics, University Hospital, Albert-Schweitzer-Campus 1, 48149 Münster, Germany.

\section{Received: 25 June 2016 Accepted: 18 August 2016} Published online: 26 August 2016

\section{References}

1. Berbari EF, Hanssen AD, Duffy MC, Steckelberg JM, Ilstrup DM, Harmsen WS Osmon DR. Risk factors for prosthetic joint infection: case-control study. Clin Infect Dis. 1998:27:1247-54.

2. Dowsey MM, Choong PFM. Obese diabetic patients are at substantial risk for deep infection after primary TKA. Clin Orthop Relat Res. 2009:467:1577-81.

3. Jämsen $E$, Huhtala $H$, Puolakka T, Moilanen T. Risk factors for infection after knee arthroplasty. A register-based analysis of 43,149 cases. J Bone Joint Surg Am. 2009:91:38-47.

4. Jämsen $E$, Varonen M, Huhtala H, Lehto MUK, Lumio J, Konttinen YT, Moilanen T. Incidence of prosthetic joint infections after primary knee arthroplasty. J Arthroplasty. 2010;25:87-92.

5. Lai K, Bohm ER, Burnell C, Hedden DR. Presence of medical comorbidities in patients with infected primary hip or knee arthroplasties. J Arthroplasty. 2007;22:651-6

6. Peersman G, Laskin R, Davis J, Peterson M. Infection in total knee replacement: a retrospective review of 6489 total knee replacements. Clin Orthop Relat Res. 2001:392:15-23.

7. Suzuki G, Saito S, Ishii T, Motojima S, Tokuhashi Y, Ryu J. Previous fracture surgery is a major risk factor of infection after total knee arthroplasty. Knee Surg Sports Traumatol Arthrosc. 2011;19:2040-4.

8. Winiarsky R, Barth P, Lotke P. Total knee arthroplasty in morbidly obese patients. J Bone Joint Surg Am. 1998;80:1770-4.

9. Zimmerli W, Trampuz A, Ochsner PE. Prosthetic-joint infections. N Engl J Med. 2004:351:1645-54.

10. Koyonos L, Zmistowski B, Della Valle CJ, Parvizi J. Infection control rate of irrigation and débridement for periprosthetic joint infection. Clin Orthop Relat Res. 2011;469:3043-8.

11. Bengtson S, Knutson K. The infected knee arthroplasty. A 6-year follow-up of 357 cases. Acta Orthop Scand. 1991;62:301-11.

12. Gill GS, Joshi AB. Long-term results of cemented, posterior cruciate ligament retaining total knee arthroplasty in osteoarthritis. Am J Knee Surg. 2001;14:209-14.

13. Höll S, Schlomberg A, Gosheger G, Dieckmann R, Streitbuerger A, Schulz D, Hardes J. Distal femur and proximal tibia replacement with megaprosthesis in revision knee arthroplasty: a limb-saving procedure. Knee Surg Sports Traumatol Arthrosc. 2012:20:2513-8.

14. Iorio R, Williams KM, Marcantonio AJ, Specht LM, Tilzey JF, Healy WL. Diabetes mellitus, hemoglobin A1C, and the incidence of total joint arthroplasty infection. J Arthroplasty. 2012;27:726-9.e1.

15. Isiklar ZU, Landon GC, Tullos HS. Amputation after failed total knee arthroplasty. Clin Orthop Relat Res. 1994:299:173-8.

16. Kramhøft M, Bødtker S, Carlsen A. Outcome of infected total knee arthroplasty. J Arthroplasty. 1994:9:617-21.

17. Pelt CE, Grijalva R, Anderson L, Anderson MB, Erickson J, Peters CL. Twostage revision TKA is associated with high complication and failure rates. Adv Orthop. 2014;2014:659047.
18. Sakellariou VI, Poultsides LA, Vasilakakos T, Sculco P, Ma Y, Sculco TP. Risk factors for recurrence of periprosthetic knee infection. J Arthroplasty. 2015;30:1618-22.

19. Cha MS, Cho SH, Kim DH, Yoon HK, Cho HS, Lee DY, et al. Two-stage total knee arthroplasty for prosthetic joint infection. Knee Surg Relat Res. 2015:27:82-9.

20. Massin P, Delory T, Lhotellier L, Pasquier G, Roche O, Cazenave A, Estellat C, Jenny JY. Infection recurrence factors in one- and two-stage total knee prosthesis exchanges. Knee Surg Sports Traumatol Arthrosc. 2015. [Epub ahead of print]

21. Parvizi J, Gehrke T, Chen AF. Proceedings of the international consensus on periprosthetic joint infection. Bone Jt J. 2013;95-B:1450-2.

22. Virolainen $P$, Lähteenmäki H, Hiltunen A, Sipola E, Meurman $O$, Nelimarkka O. The reliability of diagnosis of infection during revision arthroplasties. Scand J Surg. 2002:91:178-81.

23. Zimmerli W, Moser C. Pathogenesis and treatment concepts of orthopaedic biofilm infections. FEMS Immunol Med Microbiol. 2012;65:158-68.

24. Mittal Y, Fehring TK, Hanssen A, Marculescu C, Odum SM, Osmon D. Twostage reimplantation for periprosthetic knee infection involving resistant organisms. J Bone Joint Surg Am. 2007:89:1227-31.

25. Mortazavi SMJ, Vegari D, Ho A, Zmistowski B, Parvizi J. Two-stage exchange arthroplasty for infected total knee arthroplasty: predictors of failure. Clin Orthop Relat Res. 2011;469:3049-54

26. Romanò $\mathrm{CL}$, Gala L, Logoluso N, Romanò D, Drago L. Two-stage revision of septic knee prosthesis with articulating knee spacers yields better infection eradication rate than one-stage or two-stage revision with static spacers. Knee Surg Sports Traumatol Arthrosc. 2012;20:2445-53.

27. Sherrell JC, Fehring TK, Odum S, Hansen E, Zmistowski B, Dennos A, Kalore $\mathrm{N}$, Consortium PI. The Chitranjan Ranawat Award: fate of two-stage reimplantation after failed irrigation and débridement for periprosthetic knee infection. Clin Orthop Relat Res. 2011:469:18-25.

28. Wroblewski BM. One-stage revision of infected cemented total hip arthroplasty. Clin Orthop Relat Res. 1986:211:103-7.

29. Stammers J, Kahane S, Ranawat V, Miles J, Pollock R, Carrington RWJ, Briggs T, Skinner JA. Outcomes of infected revision knee arthroplasty managed by two-stage revision in a tertiary referral centre. Knee. 2015;22:56-62.

30. Wu CH, Gray CF, Lee GC. Arthrodesis should be strongly considered after failed twostage reimplantation TKA. Clin Orthop Relat Res. 2014; 472:3295-304.

31. Röhner E, Windisch C, Nuetzmann K, Rau M, Arnhold M, Matziolis G. Unsatisfactory outcome of arthrodesis performed after septic failure of revision total knee arthroplasty. J Bone Joint Surg Am. 2015;97:298-301.

32. Bauman RD, Lewallen DG, Hanssen AD. Limitations of structural allograft in revision total knee arthroplasty. Clin Orthop Relat Res. 2009:467(3):818-24.

33. Ricciardi BF, Oi K, Trivellas M, Lee YY, Della Valle AG, Westrich GH, Survivorship of extensor mechanism allograft reconstruction after total knee arthroplasty. J Arthroplasty. 2016. [Epub ahead of print]

34. Kubista B, Hartzler RU, Wood CM, Osmon DR, Hanssen AD, Lewallen DG. Reinfection after two-stage revision for periprosthetic infection of total knee arthroplasty. Int Orthop. 2012;36:65-71.

35. Watts CD, Wagner ER, Houdek MT, Osmon DR, Hanssen AD, Lewallen DG, Mabry TM. Morbid obesity: a significant risk factor for failure of two-stage revision total knee arthroplasty for infection. J Bone Joint Surg Am. 2014;96, e154.

36. Houdek MT, Wagner ER, Watts CD, Osmon DR, Hanssen AD, Lewallen DG, Mabry TM. Morbid obesity: a significant risk factor for failure of two-stage revision total hip arthroplasty for infection. J Bone Joint Surg Am. 2015;97:326-32.

37. Singh JA, Houston TK, Ponce BA, Maddox G, Bishop MJ, Richman J, Campagna EJ, Henderson WG, Hawn MT. Smoking as a risk factor for shortterm outcomes following primary total hip and total knee replacement in veterans. Arthritis Care Res. 2011;63:1365-74 